\title{
Polyphenols as acetylcholinesterase inhibitors: Structural specificity and impact on human disease
}

\author{
Luísa Bivar Roseiro ${ }^{\mathrm{a}, \mathrm{b}, *}$, Amélia Pilar Rauter $^{\mathrm{b}}$ and Maria Luísa Mourato Serralheiro ${ }^{\mathrm{b}}$ \\ ${ }^{a}$ Laboratório Nacional de Energia e Geologia - Unidade de Bioenergia (LNEG-UB), Lisboa, Portugal \\ ${ }^{\mathrm{b}}$ Faculdade de Ciências, Centro de Química e Bioquímica/Departamento de Química e Bioquímica, Universidade \\ de Lisboa, Lisboa, Portugal
}

\begin{abstract}
The present review focuses on the emerging evidence regarding the potential of polyphenols to act as acetylcholinesterase inhibitors. This enzyme plays a fundamental role in the body and its inhibition may play a role in the control of various pathologies, including Myasthenia gravis, Glaucoma and Alzheimer's disease. Polyphenols are present throughout the human diet and their potential effects in ameliorating the quality of life and to prevent human ageing are the subject of numerous and varied research. In this review we outline the potential influence of polyphenols on acetylcholinesterase with a particular view to describing their actions in the brain. Following an introduction to the biochemical actions of the enzyme and its active site, we will present an overview of the reported actions of polyphenols, in particular flavonoids and tannins, to act as acetylcholinesterase inhibitors. We will also highlight structure-activity relationships and how metabolism of polyphenols during absorption affects their function. Finally, we discuss the evidence for some foods to possess acetylcholinesterase inhibitor activity.
\end{abstract}

Keywords: Acetylcholinesterase inhibitors, polyphenols, flavonoids, tannins, neurodegenerative disorders

\section{Introduction}

Acetylcholinesterase (AChE) is an acetylcholine hydrolase enzyme (acetylcholine acetylhydrolase E.C. 3.1.17) with esterase activity, localized in the synaptic gaps of the central and peripheral nervous system. This membrane bound enzyme is projected into the synapse and terminates nervous impulses by catalysing the hydrolysis of the neurotransmitter acetylcholine, a neurotransmitter of cholinergic system, which amongst other roles is involved in memory formation [1]. It is a serine hydrolase with a catalytic triad, similar to other serine proteases and, although it was isolated from Torpedo californica (TcAChE) and its 3D structure was

*Corresponding author: Luísa Bivar Roseiro, Tel.: +351 21 0924600 ext. 4279; Fax: +351 2171636 36; E-mail: luisa.roseiro@lneg.pt. elucidated in 1991, the role of this enzyme in several diseases was ascertained years earlier.

Acetylcholinesterase inhibitors (AChEI) are used clinically to counteract various pathologies, including Myasthenia gravis, Glaucoma, Lewy body dementia and Alzheimer's disease [2]. Treatment is known to improve symptoms by enhancing cholinergic functions and increasing the amount of acetylcholine present in cholinergic synapses. To be effective inhibitors must reversibly bind to the active site of the enzyme as irreversible binding may lead to severe consequences, including death. For example, sarin gas binds covalent bonds irreversibly to the active site of the enzyme causing death on prolonged exposure [1]. The use of reversible acetylcholinesterase inhibitors has attracted particular attention, in particular for the treatment of Alzheimer-type dementia and has been the subject of extensive research and clinical investigation. Several 
<smiles>Nc1c2c(nc3ccccc13)CCCC2</smiles>

a) Tacrine

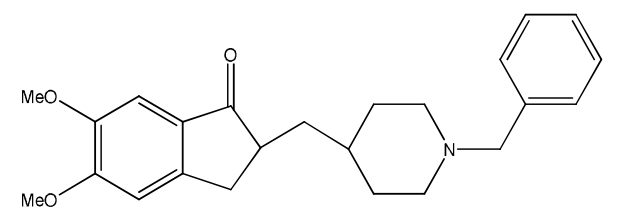

(Dimethoxyindanine Piperidine Benzyl)<smiles>COc1ccc2c3c1O[C@H]1C[C@H](O)CC[C@@]31CCN(C)C2</smiles>

b) Galantamine

c) Donepezil<smiles>CCN(C)C(=O)Oc1cccc(C(C)(C)N(C)C)c1</smiles>

e) Rivastigmine

Fig. 1. Acetylcholinesterase inhibitors approved by FDA.

compounds (Fig. 1) have been approved for alleviating the symptoms of the disease [3]. However, synthetic AChE inhibitors such as physostigmine, tacrine and donepezil have been reported to have adverse effects, such as hepatotoxicity and gastrointestinal complaints. Indeed, it has proved difficult to develop compounds to exclusively inhibit $\mathrm{AChE}$ in the brain without effecting other organs, or even other biochemical processes.

Numerous plant extracts have been investigated for their potential to treat cognitive disorders and neurodegenerative diseases. Galantamine was the first compound isolated from a plant source that was found to possess powerful AChE inhibitor activity, and although it was not without its secondary effects it is in clinical use. As such there is interest in the development of new AChE inhibitors and among these non-alkaloid compounds, including polyphenols have emerged as promising candidates. Polyphenols are an ubiquitous group of plant metabolites with $\sim 10,000$ structures identified to date. Although traditionally regarded as non-nutrients because of their astringent taste or cause of browning, polyphenols and other food phenolics has been the subject of increasing interest due to their health benefits [4]. The present review addresses the emerging evidence regarding the potential for polyphenols to act as acetylcholinesterase inhibitors. In doing so, we will highlight the function of AChE before assessing the direct inhibitory capacity of polyphenols and whether diets rich in these compounds might have beneficial effects in alleviating specific disorders associated with AChE activity.

\section{Acetylcholinesterase enzyme}

Isolated from Torpedo californica, the acetylcholinesterase enzyme ( $T c \mathrm{AChE})$ is a protein with 501 amino acid residues having an ellipsoid shape with dimensions $\sim 45 \AA$ by $60 \AA$ by $65 \AA$ (for a complete description see [5]). The active site (detailed in Fig. 2), is located in a deep and narrow gorge of $20 \AA$ that becomes larger in the bottom, where the catalytic site is located. The structure of the active site was determined from studies carried out on protein extracted from Torpedo californica and Electrophorus eel, which are structurally homologous to that of the vertebrate [6] and human enzyme [7]. From these studies it was evident that the active site has two sub-sites, the esteratic (ES), comprising the catalytic site and the anionic 


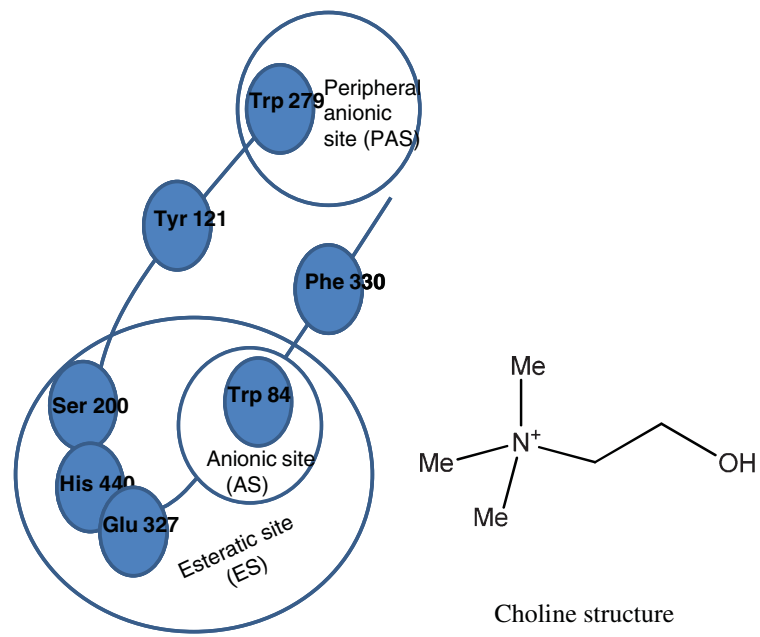

Fig. 2. Scheme of AChE active gorge (adapted from [7]) and Choline structure.

(AS) [1]. The catalytic triad of this enzyme, located in the esteratic subsite, is composed by $\mathrm{Ser}^{200}$, $\mathrm{His}^{440}$ and $\mathrm{Glu}^{327}$ in TcAChE [5], or $\mathrm{Ser}^{203}$, $\mathrm{His}^{447}$ and $\mathrm{Glu}^{334}$ in mammals [8]. The anionic sub-site is the site known to bind the choline moiety and comprises $\operatorname{Trp}^{84}, \mathrm{Phe}^{330}$ and Glu ${ }^{199}$ in TcAChE [9]. The esteratic sub-site is equivalent to the serine-binding site in other serine proteases. The $\operatorname{Ser}^{200}$ residue initiates the catalytic process [10], and the imidazole function of His participates in this process through a mechanism involving acid-base catalysis [1]. The quaternary moiety of choline (Fig. 2) seems to bind through interactions with $\pi$-electrons from the aromatic residues along the gorge, mainly with $\operatorname{Trp}^{84}$ [5].

Besides these two sub-sites, the active site also contains another location known as Peripheral Anionic Site (PAS), at the entrance of the gorge, which comprises another set of aromatic residues, $\mathrm{Tyr}^{72}, \mathrm{Tyr}^{124}$, $\mathrm{Trp}^{286}, \mathrm{Tyr}^{341}$ and $\mathrm{Glu}^{285}$, together with $\mathrm{Asp}^{74}$ (in human AChE), or Tyr ${ }^{70}, \operatorname{Tyr}^{121}, \operatorname{Trp}^{279}, \mathrm{Tyr}^{334}, \mathrm{Asp}^{72}$ (in TcAChE). This site is where the inhibitor molecules are "selected" to modulate the catalytic activity of the enzyme [11] and several studies have revealed that binding to the PAS sub-site could change the conformation of the active site, thus inhibiting enzyme activity [12]. It has been proposed that the indole moiety of $\operatorname{Trp}^{286}$ (Trp ${ }^{279}$ in TcAChE) might interact via stacking, aromatic-aromatic or via $\pi$-cation attractions, along with the involvement of the carboxylate of $\mathrm{Asp}^{74}$ (in charge-charge or H-bond interactions) [12] to confer inhibitory activity. All these residues participate in the inhibition process, by preventing substrates from entering the catalytic site by blockage of the catalytic gorge [7].

Aromatic ring moieties are suggested to be involved in the selection and stabilization of the positive charge of the quaternary group in the acetylcholine through $\pi$-electrons stabilization in a process called "aromatic guidance". The effect of AChE inhibition on ACh can be depicted from the scheme shown in Fig. 3.

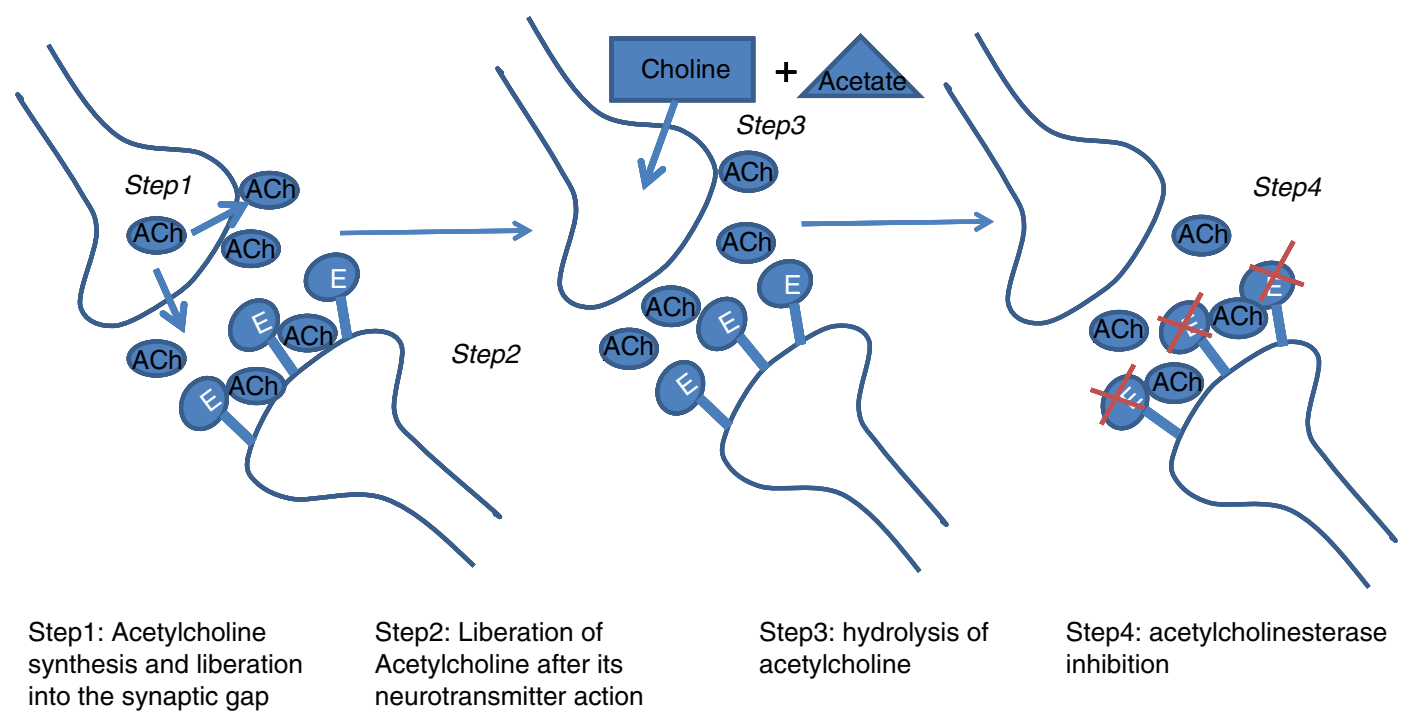

Fig. 3. Effect of AChE inhibition on ACh in the synaptic gap. 


\section{Acetylcholinesterase and its inhibition: Relevance to human disease}

As referred above, acetylcholinesterase inhibitors have several clinical applications, namely in facilitating the digestive process, as well as in disorders such as Myasthenia gravis, Glaucoma and Alzheimer's disease. The inhibition of AChE localized in the neuromuscular junctions [13, 14], increases muscle contraction thus helping the digestive activity by enhancing gastrointestinal motility $[15,16]$. Via a similar mechanism, AChE inhibitors present in neuromuscular junctions are also used to reverse neuromuscular block after anaesthesia [17]. AChE inhibitors were first used in 1932 in the Myasthenia gravis disease to improve patient conditions [18], and in 1938 the process was approved and applied to treat people suffering from this disease [19]. Later in 1960, antibodies against acetylcholine receptors were produced in this disorder and such immunosuppressive methods are still in use [20]. AChE inhibitors have also been used to treat Glaucoma [2, 21], where their use reduces pathology by decreasing the intra-ocular pressure that results in death of retinal ganglion cells. In this case, inhibitors lead to structural protection of retinal ganglion cells from the ocular hypertension.

Loss of acetylcholine signalling in the brain correlates with the severity of Alzheimer's disease (AD), the most common form of dementia in elderly people. There are several AChE inhibitors that have been designed and clinically approved to inhibit the breakdown of acetylcholine in the brain, thus leading to increases in cholinergic neurotransmitter activity and for alleviating the symptoms of Alzheimer's disease. AD is a complex biochemical process [22, 23] for which there is no cure. The administration of cholinesterase inhibitors is based on the cholinergic hypothesis, briefly meaning that the loss of cholinergic function in the central nervous system is associated with the cognitive decline in AD (reviewed in [24]). This loss in cholinergic function leads to a gradual loss of functional neurons in the brain of elderly people [25]. Many factors may be associated/correlated with this loss of cholinergic activity, including amyloid- $\beta$ peptide $(A \beta)$ formation and tau protein aggregation (reviewed in [26]), excessive transition metals [27] and oxidative stress [28]. Interestingly, AChE inhibitors have been observed to affect the "amyloid cascade" [29], in which insoluble $A \beta$-peptide is deposited in the brain [30]. However, AChE may also be involved in the formation of $A \beta$-peptides [31] accelerating its formation and it appears that the PAS of the enzyme is crucial for this activity [32].

Although surgical interventions have been used effectively to treat patients suffering from $\mathrm{AD}$ by improving cerebral blood flow (CBF) [33], presently invasive surgical intervention is not an option in all patients and other mechanisms are also not wholly effective [34]. Thus there is still a requirement for additional drug treatments such as AChE inhibitors.

\section{Structural features defining the inhibition of acetylcholinesterase}

There are only a few studies that define the molecular mechanisms of acetylcholinesterase inhibition by the polyphenols. Docking studies carried out with the potent inhibitor donepezil (Dnp) and TcAChE have shed some light on this mechanism [35]. Donepezil fits inside the gorge extending from the anionic subsite at the bottom, to the peripheral anionic site at the entrance. The compound has a dimethoxyindanone moiety, which orients itself towards the entrance establishing bonds with the PAS site of the enzyme, more precisely with $\operatorname{Trp}^{279}$ (Fig. 1c) and a strong connection with this residue appears crucial for inhibition activity [35]. The benzyl ring is oriented towards the bottom of the gorge making $\pi-\pi$ stacking interactions with the $\operatorname{Trp}^{84}$, occupying the binding site for the quaternary group of acetylcholine, preventing its interaction with the catalytic triad. Another example of the inhibitory orientation within the AChE gorge came from rivastigmine docking studies. Here, the carbamyl moiety of the drug is covalently linked to the TcAChE active site and the (1-(dimethylamino)ethyl)phenoxy leaving group is oriented towards the anionic site [36]. Furthermore, studies with choline derivatives of caffeic acid (Fig. 4) have revealed that the presence of a methyl group increases the inhibitory activity [37], as one of the methoxy groups orientates towards the $\operatorname{Trp}^{279}$ residue at the PAS sub-site, as is also the case with donepezil.

Flavonoid orientation inside the enzyme gorge also looks similar to that presented by donepezil. Flavonoids have an aromatic ring (B-ring) (see Fig. 5), which contains $-\mathrm{OH}$ groups that establish bonds with the PAS of the enzyme. Flavonoids appear not to induce modifications in the ternary structure of the enzyme, meaning that the inhibition process occurs due to the 


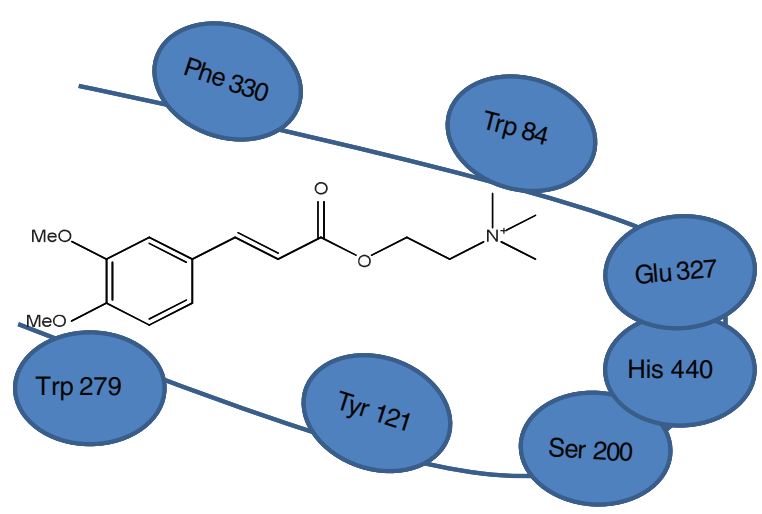

Fig. 4. Scheme of molecular interaction of a caffeic acid choline ester at the active gorge of AChE.

blockage of the entrance to the active site. Quercetin (Fig. 6a) has been found to establish several hydrogen bonds with the amino acid residues at the anionic sub-site. The carbonyl moiety in $\mathrm{C}$ ring and $-\mathrm{OH}$ group in $\mathrm{C} 5$ position of the A-ring establishes hydrogen bonds with $\mathrm{Tyr}^{133}$, whilst $\mathrm{C} 3-\mathrm{OH}$ group in the $\mathrm{C}$ ring hydrogen bonds with the $\operatorname{Trp}^{86}$ residue in the anionic site. Finally the $-\mathrm{OH}$ group of the phenyl side (B-ring) shows hydrogen bonding with residues in the PAS sub-site [39]. Such H-binding confers flavonoids with enhanced $\mathrm{AChE}$ inhibitor activity relative to other phenolic compounds like caffeic acid (Fig. 6b) and rosmarinic acid (Falé PL, Ascensão L, Serralheiro MLM, Haris PI, unpublished data). The existence of an $-\mathrm{OH}$ group in $\mathrm{C} 3$ position of the $\mathrm{C}$ ring appears to be crucial in increasing inhibition activity. Indeed, docking studies with flavonoids indicate that amino acid binding in the active gorge is more favourable with a greater number of hydrogen bonds [39]. The interactions established between the $\mathrm{C} 3-\mathrm{OH}$ group and $\operatorname{Tr} \mathrm{p}^{86}$ may explain why rutin and kaempferol $3-O-\beta-\mathrm{D}$ galactoside that have this $-\mathrm{OH}$ group conjugated, show lower activity than quercetin [39]. Interactions between the $\operatorname{Trp}^{279}$ at the PAS sub-site have also been reported with the aromatic ring of choline ester of 3,4dimethoxycinnamic acid (Fig. 6c) [37].

In summary, it seems that phenolic compounds having structural motifs similar to caffeic acid are capable of fitting into the gorge of the active site of AChE by positioning the aromatic ring into the PAS sub-site, with the exception of phenolics like 2-hydroxy$6-\left[10^{\prime}(Z)\right.$-heptadecenyl]benzoic acid, in which the aromatic ring orientates towards the anionic sub-site [12]. Flavonoids that possess a free $\mathrm{OH}$-group at

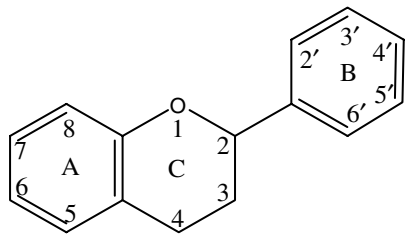

Fig. 5. Structure-type and numbering of some flavonoids classes.

C3 position are more inhibitory compared to their $\mathrm{C} 3-\mathrm{OH}$ glycosylated counterparts and those having no $\mathrm{C} 3-\mathrm{OH}$ group, such as luteolin and apigenin. Flavonoids, as caffeic acid, orientate within the pocket with their B ring facing the PAS site. However, one should bear in mind that most phenolic compounds are metabolised during absorption in the gastrointestinal tract and again in the liver, leading to $O$-methylated, sulphated and glucuronide forms. These metabolites, along with those produced in the large intestine via the actions of the bacteria, are chemically different from the forms found in food and those predominantly tested for AChE inhibitory activity to date. Future work in this area must continue to consider and investigate the actions of these metabolites that reach the circulatory system and other target organs, as they may not inhibit in the same manner.

\section{Acetylcholinesterase inhibitors from natural sources}

Despite issues regarding absorption and metabolism and precise mechanisms of action in vivo, the screening for acetylcholinesterase inhibitors found in plants is valid in highlighting those compounds with the most promise of biological activity. For example, galantamine (Fig. 1a) is an alkaloid isolated from Galanthus spp. [40] that is now used clinically. The discovery of this compounds provoked the search for new compounds that might be useful as acetylcholinesterase inhibitors for clinical use. Ethno-pharmacological approaches and bioassay-guided isolation have proven effective in identifying potential AChE inhibitors from plant sources. Mukherjee et al. [41] highlights the plants and/or their active constituents reported to have AChE inhibitory activity (\% inhibition; concentration), with the most significant inhibitors thought to be alkaloids and a few glycosides. Other plants with reported CNS activity (used in traditional South African medicine to treat various mental conditions) 
<smiles>O=C1c2c(O)cc(O)cc2OC(c2ccc(O)c(O)c2)C1O</smiles>

a) Quercetin<smiles>O=C(O)/C=C/c1ccc(O)c(O)c1</smiles>

b) Caffeic acid<smiles>COc1ccc(/C=C/C(=O)OCC[N+](C)(C)C)cc1OC</smiles>

c) Choline ester of 3,4-dimethoxy cinnamic acid<smiles>Oc1cc(O)cc(O)c1</smiles>

d) Phloroglucinol<smiles>Oc1cc(O)cc(Oc2c(O)cc(O)c3c2Oc2c(O)cc(O)c(-c4c(O)cc(O)c5c4Oc4c(O)cc(O)c(Oc6cc(O)cc(O)c6)c4O5)c2O3)c1</smiles>

e) 6,6-Bieckol

Fig. 6. Sctructures of different phenolics compounds with AChE inhibition: 1 flavonoid (quercetin) 1 phenolic acid (caffeic acid), 1 caffeic acid choline ester (choline ester of 3,4-dimethoxy cinnamic acid), phloroglucinol and a phloroglucinol-based polyphenol (6,6-bieckol).

are also rich sources of such alkaloids, although many of these are known to be toxic [42].

Many phenolic compounds have also been investigated for their CNS function, including a wide range of flavonoids. For example, a number are reported to exert sedative/anxiolytic effects via direct binding to $\mathrm{GABA}_{\mathrm{A}}$ receptors in animal model studies, as is the case of 6-hydroxyflavone [43] and a tri-substituted benzoflavone moiety from Passiflora incarnata [44].
Oroxylin A (5,7-dihydroxy-6-methoxyflavone), a flavonoid found in the roots of Scutellaria baicalensis, has also been shown to exert cognitive enhancement via antagonistic $\mathrm{GABA}_{\mathrm{A}}$ receptor binding and resultant cholinergic up-regulation [45]. Furthermore, a recent study indicated that trans-resveratrol exerts an anti-depressant-like action via monoamine oxidase inhibition and resultant increase in levels of 5-HT, DA, and noradrenaline in select brain areas [46]. 


\section{Polyphenols as acetylcholinesterase inhibitors}

Plant phenolics are well known to play crucial roles in plant ecology and physiology and play important roles in the prevention of many chronic diseases. Perhaps the oldest medical application of phenolic compounds was their use as antiseptics and sunscreens, due to the effective absorption of the UV-B radiation (between 280 and $315 \mathrm{~nm}$ ) by phenolic groups $[4,47]$. More recently polyphenols such as flavonoids have been investigated for their acetylcholinesterase inhibitory activity [48], along with other phenolic compounds [39, 48-53]. For example, the phenolic extracts of 12 traditional medicinal plants from southern Africa have been assessed for their acetylcholinesterase inhibitory potential [54], with five plants showing good cholinesterase inhibitory activities, but identification of these active compounds was not indicated. Furthermore, the non-aqueous extracts of seven medicinal plants commonly used for the treatment of painrelated ailments in South Africa have been assessed for their anti-inflammatory, anticholinesterase and antioxidant properties [55], with alkaloids and phenolics being suggested as the bioactive components. During a screening for AChE inhibitors in 180 medicinal plants, various active polyphenols were highlighted, including tiliroside, 3-methoxyquercetin, quercitrin

Table 1

Plant extracts with AChE inhibitory activity

\begin{tabular}{lc}
\hline Plant & Reference \\
\hline Agrimonia pilosa ledeb & {$[51]$} \\
Mentha avensis & {$[62]$} \\
Buddleja davidii & \\
Scutellaria taxa & {$[57]$} \\
Salvia taxa & {$[60,70]$} \\
Juniperus sp. & {$[71]$} \\
Fagopyrum esculentum & {$[72]$} \\
Calendula sp. & {$[73]$} \\
Laurocerasus officinallis & {$[74]$} \\
Catharanthus roseus & {$[78]$} \\
Foeniculum vulgare & \\
Mentha spicata & \\
Mentha pulegium & {$[80]$} \\
Rosmarinus officinalis & \\
Thymus serpyllum & {$[81]$} \\
Cymbopogon schoenanthus & {$[82,88]$} \\
Camelia sinensis & {$[85]$} \\
Hypericum sp. & {$[87]$} \\
Pseuderanthemum palatiferum & {$[100]$} \\
Plectranthus barbatus & \\
\hline
\end{tabular}

and quercetin [51], whilst galangin was identified in a separate study [52]. Recently various papers have appeared concerning the evaluation of AChE inhibitory activity in medicinal plants (Table 1), many of which have also been used traditionally to promote memory and inhibit neurological disorders [56-60]. However, whilst these studies highlight various plant extracts of possessing AChE inhibitor activity, in many cases the specific compounds responsible for inhibitory activity are not precisely determined.

Despite this the effects of curcumin, found in turmeric, (-)-epigallocatechin-3-gallate (EGCG), the main active phenolic compound in green tea, and resveratrol have all been proposed as having actions on the brain $[63,64]$. With regards to the AChE inhibition, the flavanone naringenin, a major flavonoid present in citrus has been shown to exert AChE inhibitory activity in vitro and anti-amnesic activity in vivo [65]. The flavonol quercetin [67] has not been tested for its inhibitory activity in vivo but also appears to influence cerebral blood flow and cholinergic dysfunction in brain [66]. The authors suggested that consumption of a diet rich in quercetin may prevent dementia associated with vascular and neurodegenerative disorders, such as Alzheimer's disease. However, whilst various (poly)phenols have been proposed to inhibit AChE activity (Table 2) future work is required to establish whether these compounds reach the brain and directly affect AChE activity.

\section{Screening plant extracts for acetylcholinesterase inhibition}

The previous section highlighted work with some single polyphenols that showed promising AChE inhibitory activity. However, a significant amount of work has also been conducted using foods extracts to screen for potential foods with the view to isolating novel AChE inhibitors. Multiple phenolic compounds coexist in foods (for an overview of dietary flavonoids, see [38]). Fruits, vegetables, beverages (tea, juice, wine) and several herbs contain an array of polyphenols that exhibit a range of biological activities and are thought to contribute to the beneficial effects of fruit and vegetable intake. In recent years there has been a great deal of interest in the action of such polyphenols against neurodegenerative diseases, such as Alzheimer's disease. Many plants have been used traditionally as therapeutic effects against dementia 
Table 2

Natural phenolic compounds as AChE inhibitors

\begin{tabular}{llr}
\hline Compound & Source & Reference \\
\hline Tiliroside & Agrimonia pilosa ledeb & {$[51]$} \\
3-methoxyquercetin & Agrimonia pilosa ledeb & {$[51]$} \\
Quercetin & Many fruits, vegetables, beverages & {$[51,66]$} \\
Quercitrin & & {$[52]$} \\
Galangin & Traditional Chinese medicines & {$[62]$} \\
Linarin & Mentha avensis; Buddlejja daviidi & {$[63]$} \\
Curcumin & Tumeric & {$[63]$} \\
Resveratrol & Red wine & {$[65]$} \\
Naringenin & Citrus junus & {$[85]$} \\
Chlorogenic acid & & \\
Rutin & Hypericum species & {$[61]$} \\
Hyperoside & & {$[63,88,93]$} \\
Isoquercitrin & & {$[95]$} \\
Savianolic acid B & Radix Salvia miltiorrhiza \\
Gallocatechins: EC, EGC, EGCG & Camellia sinensis Diospyros kakis & {$[100]$} \\
Phlorotannins: 6,6-bieckol, diphlorethohydroxycarmalol & Marine brown algae (Phaeophyta) \\
Rosmarinic acid & Plectranthus barbatus & \\
\hline
\end{tabular}

and as part of these studies have also been investigated for their acetylcholinesterase inhibitory activity in vitro (Table 1). These include, Scutellaria $\mathrm{L}$ taxa and Salvia taxa [57, 69, 70] and herbal coffees [75, 76], with results proving promising but not conclusive. One of the reasons for this may be that the majority of anti-acetylcholinesterase tests performed in vitro were conducted on the organic extracts of these plants and may not be fully representative of possible effects after consumption of whole foods or beverages. Again, the active compounds were not identified and no account of absorption and metabolism of compounds contained within these extracts were made.

Similar shortcomings apply to in vivo trials, where an extract of blueberry (methanol, acetic acid and water: $25: 1: 24$ ) showed effects on cognitive performance, brain oxidative status and acetylcholinesterase activity in mice [77]. As most polyphenols in blueberry would be expected to be more soluble in an aqueous medium, the influence of an aqueous extract, or whole blueberry may be more representative of the biological affects in vivo. Whilst there are also physiological shortcomings of experiments testing aqueous extracts from traditional medicinal plants for $\mathrm{AChE}$ inhibition in vitro [61, 78-84], they do at least highlight the presence of potential interesting compounds within these complex extract mixtures. Indeed, Hernandez et al. [85] postulated that the active AChE inhibitors in Hypericum were phenolics such as chlorogenic acid, rutin, hyperoside, isoquercitrin and quercitrin, which was confirmed by determining the AChE inhibitory activity of the pure compounds. Again, before firm conclusions can be drawn of the significance of these findings, the absorption and metabolism of these components needs to be factored in.

A few in vivo studies have also evaluated the effect of polyphenol-rich extracts on acetylcholinesterase activity. Intervention with a water-soluble extract of propolis led to significant inhibition of hippocampal AChE activity along with cognitive improvements that may be mediated by apigenin, kaempferol and luteolin [86]. In addition, an aqueous extract of Pseuderanthemum palatiferum, a polyphenol-rich tea used predominantly in Thailand, has also been shown to inhibit $\mathrm{AChE}$ in the brain (hippocampus), serum and red blood cells in rats [87]. An extract of the more widely consumed green tea $(0.5 \%$; containing $60 \%$ flavanols, most prominently (-)-epigallocatechin3-gallate) was effective in enhancing learning and memory in aged rats and also the selective inhibition of acetylcholinesterase [88]. These results are in agreement with other studies in scopolamine-treated mice, where tea polyphenols significantly reversed cognitive deficits and exhibited a dramatic inhibitory effect on AChE activity [89].

Whilst not yet investigated AChE inhibition activity, berry extracts containing high levels of anthocyanins [90] and cocoa flavanols [91, 92] have also been shown to exert promising effects against age-related cognitive decrements in rodents and humans by limiting 
neurodegeneration and/or preventing normal or abnormal deteriorations in cognitive performance [93]. The mechanism of action of flavonoid-rich foods might be partly mediated by actions on brain AChE activity, as has been suggested for other, more complex flavanols such as tannins [94]. Moreover, marine brown algae (Phaeophyta) contain a variety of phloroglucinolbased polyphenols, known as phlorotannins (Figs. 6d and e) and have been proposed to have health beneficial properties [95]. The 6,6-bieckol from I. okamurae (Phaeophyceae) has been shown to express potent AChE inhibitory effects, [96], although as a non-competitive inhibitor. As highlighted earlier, a significant amount of additional work is required in order to fully assess the potential for such foods and polyphenols to act as AChE inhibitors, although this activity remains a possible mechanism of action of polyphenols from these foods in vivo.

\section{Open issues and concluding remarks}

A survey of medicinal plants and their extracts in order to evaluate their medicinal and therapeutic potential have revealed that there are many polyphenols that have a potential to act as AChE inhibitors. Additionally, other sources of such compounds exist such as from agro-industrial and forest residues [97]. Extractable polyphenols from different types of vegetable biomass are of special interest as they are readily available and cheap [98]. Recent studies performed on the water extracts of olive pomace and carob kibbles (two biomass residues from food processing and agroindustrial transformation), indicate that both extracts are rich in polyphenols and express significant acetylcholinesterase inhibitory action (Roseiro LB, Rauter AP, Serralheiro MLM, unpublished data). Hydroxytyrosol, present in the olive pomace extract, had $\mathrm{IC}_{50}$ value of $0.28 \mathrm{mg} / \mathrm{mL}$ compared to $0.22 \mathrm{mg} / \mathrm{mL}$ for the pomace extract, suggesting that this biomass is a promising source for a therapeutic agent or functional ingredient in foods, with hydroxytyrosol as the active principle.

Studies to date suggest that diets rich in phenolic compounds might significantly influence memory and cognition, and that part of this action may be mediated by actions on AChE activity. However, despite a series of in vitro and in vivo evidence, the majority of studies to date have failed to fully establish such an activity. Thus, future work is necessary to assess brain
AChE activity after feeding aqueous extracts or whole extracts/foods. Furthermore, when conducting in vitro studies designed to establish the active components, the issue of bioavailability and biotransformation of these compounds and their metabolites must be considered and applied (for a review on cellular uptake and metabolism of flavonoids refer to [99]). Indeed, results have indicated that such metabolism is important in defining actual activity [100, 101]. For example, AChE inhibitory activity of Plectranthus barbatus decoction, (consumed as an herbal tea) was retained after gastric juice digestion but reduced around 50\% after pancreatic digestion [100]. Rosmarinic acid, the main phenolic compound found in this extract, was detected in the brain of rats, where acetylcholinesterase activity was decreased by $30 \%$ in comparison with control animals [102]. These results indicate that rosmarinic acid may permeate the blood brain barrier and act as an acetylcholinesterase inhibitor in the brain.

As it is currently impossible to assess brain AChE inhibitory activity in human studies further animal studies are needed in order to establish which phenolic compounds or their metabolites exert AChE inhibitory activity in vivo. However, in parallel to these further investigations of which foods are capable of ameliorating cognitive function should also take place. It is worthwhile to conduct epidemiological studies regarding polyphenol intake and the progression of neurodegenerative diseases that require a lengthy incubation time before clinical manifestation [103] and variation between the geographical distributions of various neurological disorders should be compared with food polyphenolic composition data across various countries and ethnicities. Indeed, Nurk et al. report a positive relationship between the intake of various plant foods and cognitive performance in elderly people in a cross-sectional study in Norway (The Hordaland Health Study), concluding that a diet rich in plant foods, particularly vegetables or the combination of fruit and vegetables, is associated with better performance in several cognitive abilities in a dosedependent manner [104]. Whilst it is not possible to attribute these effects to AChE inhibitory activity of deliver polyphenols, such studies would further build the evidence base for the activity of such foods and diets.

Lastly, phytochemical-rich foods also contain compounds other than polyphenols, such as terpenes and alkaloids that may also be effective AChE inhibitors either alone or in synergy with phenolics. In vivo 
phytochemicals and other components will not function as single molecules in the body and may explain the AChE inhibitory activity of single compounds and extract mixtures in vitro [60, 61, 71-74, 77-79]. Evidence suggests that synergies within and between chemical groups may take place and should be considered. Of course, the neuroprotective effects attributed to the polyphenols are not only mediated by their AChE inhibitory activity, but also by other mechanisms of action, namely, anti-inflammatory activity, protection against $A \beta$-induced toxicity, MAO-B inhibiting potential, and interactions with brain cell signalling [34]. However, their ability to interact with and inhibit AChE may contribute to their reported physiological effects and knowledge about this may add weight to the evidence regarding their prophylactic/therapeutic potential to combat specific neurological disorders.

\section{Acknowledgements}

Luísa Bivar Roseiro greatly acknowledges a Post-doc grant (SFRH/BPD/46308/2008) from The Fundação para a Ciência e a Tecnologia (FCT) of the Portuguese Ministry of Science, Technology and Higher Education.

\section{References}

[1] Quinn DM. Acetylcholinesterase: Enzyme structure, reaction dynamics, and virtual transition states. Chem Rev. 1987;87:955-79.

[2] Nair VP, Hunter JM. Anticholinesterases and anticholinergic drugs. Contin Educ Anaesth Crit Care Pain. 2004;4:164-8.

[3] Racchi M, Mazzucchelli M, Porrello E, Lanni C, Govoni S. Acetylcholinesterase inhibitors: novel activities of old molecules. Pharmacol Res. 2004;50:441-51.

[4] Vermerris W, Nicholson R. Phenolic compounds and their effect in human health. In: Phenolic Compound Biochemistry. The Netherlands: Springer; 2006.

[5] Sussman JL, Harel M, Frolow F, Oefner C, Goldman A, Toker L, Silman I. Atomic structure of acetylcholinesterase from Torpedo californica: a prototypic acetylcholine-binding protein. Science. 1991;253:872-9.

[6] Bon S, Vigny M, Massoulié J. Asymmetric and globular forms of acetylcholinesterase in mammals and birds. Proc Natl Acad Sci U S A. 1979;76:2546-50.

[7] Dvir H, Silman I, Harel M, Rosenberry TL, Sussman JL. Acetylcholinesterase: from 3D structure to function. Chem Biol Interact. 2010;187:10-22.

[8] Shafferman A, Kronman C, Flashner Y, Leitner M, Grosfeld H, Ordentlich A, Gazes Y, Cohen S, Ariel N, Barak D, Harel M, Silman I, Sussman JL, Vela, B. Mutagenesis of human acetylcholinesterase. Identification of residues involved in catalytic activity and in polypeptide folding. $\mathrm{J}$ Biol Chem. 1992;267:17640-8.

[9] Harel M, Schalk I, Ehret-Sabatier L, Bouet F, Goeldner, M, Hirth C, Axelsen PH, Silmanii I, Sussman JL. Quaternary ligand binding to aromatic residues in the active-site gorge of acetylcholinesterase. Proc Natl Acad Sci U S A. 1993;90:9031-5.

[10] MacPhee-Quigley K, Taylor P, Taylor S. Primary structures of the catalytic subunits from two molecular forms of acetylcholinesterase, a comparison of NH2-terminal and active center sequences. J Biol Chem. 1985;260:1285-9.

[11] Barak D, Kronman C, Ordentlich A, Ariel N, Bromberg A, Marcus D, Lazar A, Velan B, Shafferman A. Acetylcholinesterase peripheral anionic site degeneracy conferred by amino acid arrays sharing a common core. J Biol Chem. 1994;264:6296-305.

[12] Akhtar MN, Lam KW, Abas F, Maulidiani, Ahmad S, Shah SAA, Atta-ur-Rahman, Choudhary MI, Lajis NH. New class of acetylcholinesterase inhibitors from stem bark of Knema laurina and their structural insights. Bioorg Med Chem Lett. 2011;21:4097-103.

[13] Zacks SI, Blumberg JM. The histochemical localization of acetylcholinesterase in the fine structure of neuromuscular junctions of mouse and human intercostal muscle. J Histochem Cytochem. 1961;9:317-24.

[14] Gaspersic R, Koritnik B, Crne-Finderle N, Sketelj J. Acetylcholinesterase in the neuromuscular junction. Chem Biol Interact. 1991;119-120:301-8.

[15] Jarvie E, Cellek S, Sanger G. Potentiation by cholinesterase inhibitors of cholinergic activity in rat isolated stomach and colon. Pharmacol Res. 2008;58:297-301.

[16] Kawachi M, Matsunaga Y, Tanaka T, Hori Y, Ito K, Nagahama K, Ozaki T, Inoue N, Toda R, Yoshii K, Hirayama M, Kawabata Y, Takei M. Acotiamide hydrochloride (Z-338) enhances gastric motility and emptying by inhibiting acetylcholinesterase activity in rats. Eur J Pharmacol. 2011;666: 218-25.

[17] Clark JK, Cowley P, Muir AW, Palin R, Pow E, Prosser AB, Taylor R, Zhang, MQ. Quaternary salts of e2020 analogues as acetylcholinesterase inhibitors for the reversal of neuromuscular block. Bioorg Med Chem Lett. 2002;12:2565-8.

[18] Freedman S. Antisemitism and the history of Myasthenia gravis. IMAJ- Isr Med Assoc J. 2010;12:195-8.

[19] Pearce JMS. Mary Broadfoot Walker (1888-1974): a historic discovery in Myasthenia gravis. Eur Neurol. 2005;53:51-3.

[20] Keesy JC. Myasthenia gravis: an illustrative history. N Engl J Med. 2003;348:181-2.

[21] Almasieh M, Zhou Y, Kelly ME, Casanova C, Di Polo A. Structural and functional neuroprotection in Glaucoma: role of galantamine-mediated activation of muscarinic acetylcholine receptors. Cell Death \& Disease. 2010;1:e27.

[22] Hashimoto M, Rockenstein E, Crews L, Masliah E. Role of protein aggregation in mitochondrial dysfunction and neurodegeneration in Alzheimer's and Parkinson's diseases. Neuromolecular Med. 2003;4:21-36.

[23] Salawu FK, Umar JT, Olokoba AB. Alzheimer's disease: A review of recent developments. Ann Afr Med. 2011;10: 73-9.

[24] Mesulam M. The cholinergic lesion of Alzheimer's disease: Pivotal factor or side show? Learn Mem. 2004;11:43-9. 
[25] Osborn GG, Saunderds AV. Current treatments for patients with Alzheimer's disease. J Am Osteopath Assoc. 2010;110: S16-26.

[26] Suh Y-H, Checler F. Amyloid precursor protein, presenilins, and $\alpha$-synuclein: molecular pathogenesis and pharmacological applications in Alzheimer's disease. Pharmacol Rev. 2002;54:469-525.

[27] Hedge ML, Hedge PM, Rao KS, Mitra S. Oxidative genome damage and its repair in neurodegenerative diseases: function of transition metals as a double-edged sword. J Alzheim Dis. 2011;24:183-98.

[28] Mohandas E, Rajmohan V, Raghunath B. Neurobiology of Alzheimer's disease. Indian J Psychiatr. 2009;51:55-61.

[29] Racchi M, Mazzucchelli M, Lenzken SC, Porrello E, Lanni C, Govoni S. Role of acetylcholinesterase inhibitors in the regulation of amyloid $\beta$ precursor protein (A $\beta P P)$ metabolism. Chem Biol Interact. 2005;157-158:335-8.

[30] Ohnishi S, Takano K. Amyloid fibrils from the viewpoint of protein folding. Cell Mol Life Sci. 2004;61:511-24.

[31] Inestrosa NC, Alvarez A, Perez CA, Moreno RD, Vicente M, Linker C, Casanueva OI, Soto C, Garrido J. Acetylcholinesterase accelerates assembly of amyloidbeta-peptides into Alzheimer's fibrils: possible role of the peripheral site of the enzyme. Neuron. 1996;16:881-91.

[32] Talesa VN. Acetylcholinesterase in Alzheimer's disease. Mech Aging Dev. 2001;122:1961-9.

[33] Goldsmith HS. A new approach to the treatment of Alzheimer's disease: the need for a controlled study. J Alzheim Dis. 2011;25:209-12.

[34] Ji HF, Zhang HY. Theoretical evaluation of flavonoids as multipotent agents to combat Alzheimer's disease. J Molecular Struct: THEOCHEM. 2006;767:3-9.

[35] Kryger G, Silman I, Sussman JL. Structure of acetylcholinesterase complexed with E2020 (Aricept ${ }^{\circledR}$ ): implications for the design of new anti-Alzheimer drugs. Structure. 1999;7:297-307.

[36] Bar-On P, Millard CB, Harel M, Dvir H, Enz A, Sussman JL, Silma I. Kinetic and structural studies on the interaction of cholinesterases with the anti-Alzheimer drug rivastigmine. Biochem. 2002; 41:3555-64.

[37] Šebestik J, Marques SM, Falé PL, Santos S, Arduido DM, Cardoso SM, Oliveira CR, Serralheiro MLM, Santos MA. Bifunctional phenolic-choline conjugates as anti-oxidants and acetylcholinesterase inhibitors. J Enzyme Inhib Med Chem. 2011;26:485-97.

[38] Beecher GR. Overview of Dietary Flavonoids: Nomenclature, occurrence and intake. Proceedings of the third international scientific symposium on tea and human health: Role of flavonoids in the diet. J Nutr. 2003;3248S-54S.

[39] Khan MTH, Orhan I, Senol FS, Kartal M, Sener B, Dvorská M, Smejkal M. Slapetová T. Cholinesterase inhibitory activities of some flavonoid derivatives and chosen xanthone and their molecular docking studies Chem Biol Interact. 2009; 181:383-9.

[40] Heinrich M, Teoh LH. Galanthamine from snowdrop: The development of a modern drug against Alzheimer's disease from local Caucasian knowledge. J Ethnopharmacol. 2004; 92:147-162.
[41] Mukherjee PK, Kumar V, Mal M, Houghton PJ. Acetylcholinesterase inhibitors from plants. Phytomedicine. 2007; 14:289-300.

[42] Stafford GI, Pedersen ME, van Staden J, Jager AK. Review on plants with CNS-effects used in traditional South African medicine against mental diseases. J Ethnopharmacol. 2008;119:513-37.

[43] Ren L, Wang F, Xu Z, Chan WM, Zhao C, Xue H. GABAA receptor subtype selectivity underlying anxiolytic effect of 6-hydroxyflavone. Biochem Pharmacol. 2010;79:1337-44.

[44] Dhawan K, Dhawan S, Sharma A. Passiflora: a review update. J Ethnopharmacol. 2004;94:1-23.

[45] Kim DH, Jeon SJ, Son KH, Jung JW, Lee S, Yoon BH, Lee J-J, Cho Y-W, Cheong JH, et al. The ameliorating effect of oroxylin A on scopolamine-induced memory impairment in mice. Neurobiol Learn Mem. 2007;87:536-46.

[46] Xu Y, Wang Z, You W, Zhang X, Li S, Barish P, Vernon M, Du $\mathrm{X}, \mathrm{Li} \mathrm{G}$, et al. Antidepressant-like effect of trans-resveratrol: involvement of serotonin and noradrenaline system. Eur Neuropsychopharmacol. 2010;20:405-13.

[47] Treutter D. Significance of flavonoids in plant resistance: a review. Environ Chem Lett. 2006;4:147-57.

[48] Uriarte-Pueyo I, Calvo MI. Flavonoids as acetylcholinesterase inhibitors. Curr Med Chem. 2011;18: 5289-302.

[49] Bruhlmann C, Marston A, Hostettmann K, Carrupt PA, Testa B. Screening of non-alkaloidal natural compounds as acetylcholinesterase inhibitors. Chemistry \& Biodeversity. 2004;1:819-29.

[50] Oinonen PP, Jokela JK, Hatakka AI, Vuorela PM. Linarin, a selective acetylcholinesterase inhibitor from Mentha arvensis. Fitoterapia. 2006;77:429-34.

[51] Jung M, Park M. Acetylcholinesterase inhibition by flavonoids from Agrimonia pilosa. Molecules. 2007;12: 2130-9.

[52] Guo AJY, Xie HQ, Choi RCY, Zheng KYZ, Bi CWC, Xu SL, Dong TXT, Tsim KWK. Galangin, a flavonol derived from Rhizoma Alpiniae Officinarum, inhibits acetylcholinesterase activity in vitro. Chem Biol Interact. 2010;187:246-8.

[53] Uriarte-Pueyo I, Calvo MI. Structure-activity relationships of acetylated flavone glycosides from Galeopsis ladanum L. (Lamiaceae). Food Chem. 2010;120:679-83.

[54] Adewusi EA, Steenkamp V. In vitro screening for acetylcholinesterase inhibition and antioxidant activity of medicinal plants from southern Africa. Asian Pacific Journal of Tropical Medicine. 2011;829-35.

[55] Fawole OA, Amoo SO, NdhlAla AR, Light ME, Finnie JF, Van Staden J. Anti-inflamatory, anticholinesterase, antioxidant and phytochemical properties of medicinal plants used for pain-related ailments in South Africa. J Ethnopharmacol. 2010;127:235-41.

[56] Orhan I, Senol FS, Gulpinar AR, Kartal M, Sekeroglu N, Deveci M, Kan Y, Sener B. Acetylcholinesterase inhibitory and antioxidant properties of Cyclotrichium niveum, Thymus praecox subsp. caucasicus var. caucasicus, Echinacea purpurea and E. pallida. Food Chem Toxicol. 2009;47: 1304-10.

[57] Senol FS, Orhan I, Celep F, Kahraman A, Dogan M, Yilmaz G, Sener B. Survey of 55 Turkish Salvia taxa for their 
acetylcholinesterase inhibitory and antioxidant activities. Food Chem. 2010;120:34-43.

[58] Amoo SO, Ndhlala AR, Finnie JF, Van Staden J. Antifungal, acetylcholinesterase inhibition, antioxidant and phytochemical properties of three Barleria species. South African Journal of Botany. 2011;77:435-45.

[59] Feitosa CM, Freitas RM, Luz NNN, Bezerra MZB, Trevisan MTS. Acetylcholinesterase inhibition by some promising Brazilian medicinal plants. Braz J Biol. 2011;71:783-9.

[60] Akkol EK, Orhan IE, Yesilada E. Anticholinesterase and antioxidant effects of the ethanol extract, ethanol fractions and isolated flavonoids from Cistus laurifolius L. leaves. Food Chem. 2012;131:626-31.

[61] Zhou Y, Li W, Xu L, Chen L. In: Salvia miltiorrhiza, phenolic acids possess protective properties against amyloid $\beta$-induced cytotoxicity, and tanshinones act as acetylcholinesterase inhibitors. Environ Toxicol. Pharmacol 2011; 31:443-52.

[62] Lou H, Fan P, Perez RG, Lou H. Neuroprotective effects of linarin through activation of the PI3K/Akt pathway in amyloid- $\beta$-induced neuronal cell death. Bioorg Med Chem. 2011;19:4021-7.

[63] Kennedy DO, Wightman EL. Herbal extracts and phytochemicals: Plant secondary metabolites and the enhancement of human brain function. Adv Nutr. 2011;2:32-50.

[64] Kennedy DO, Wightman EL, Reay JL, Lietz G, Okello E, Wilde AJ, Haskell CF. Effects of resveratrol on cerebral blood flow variables and cognitive performance in humans: a double-blind, placebo-controlled, crossover investigation. Am J Clin Nutr. 2010;91:1590.

[65] Heo HJ, Kim MJ, Lee JM, Choi SJ, Cho HY, Hong B, Kim E, Shin DH. Naringenin from Citrus junos has an inhibitory effect on acetylcholinesterase and as mitigating effect on amnesia. Dement Geriatr Cogn Disord. 2004;17: 151-7.

[66] Tota S, Awasthi H, Kamat PK, Nath C, Kashif Hanif K. Protective effect of quercetin against intracerebral streptozotocin induced reduction in cerebral blood flow and impairment of memory in mice. Behav Brain Res. 2010;209:73-9.

[67] Hertog MG, Hollman PC, Katan MB, Kromhout D. Intake of potentially anticarcinogenic flavonoids and their determinants in adults in The Netherlands. Nutr Cancer. 1993;20: 21-9.

[68] Shahidi F, Naczk M. Phenolics in food and nutraceuticals. CRC Press; 2004.

[69] Senol FS, Orhan I, Yilmaz G, Sener B. Acetylcholinesterase, butyrylcholinesterase, and tyrosinase inhibition studies and antioxidant activities of 33 Scutellaria L. taxa from Turkey. Food Chem Toxicol. 2010;48:781-8.

[70] Rauter AP, Branco I, Lopes RG, Justino J, Silva FVM, Noronha JP, Cabrita EJ, Brouard I, Bermejo J. A new lupene triterpenetriol and anticholinesterase activity of Salvia sclareoides. Fitoterapia. 2007;78:474-81.

[71] Orhan N, Orhan IE, Ergun F. Insights into cholinesterase inhibitory and antioxidant activities of five Juniperus species. Food Chem Toxicol. 2011;49:2305-12.

[72] Gulpinar AR, Orhan IE, Kan A, Senol FS, Celik SA, Kartal M. Estimation of in vitro neuroprotective properties and quantification of rutin and fatty acids in buckwheat
(Fagopyrum esculentum Moench) cultivated in Turkey. Food Res Int. 2011; in Press.

[73] Orhan IE, Akkol EK. Estimation of neuroprotective effects of Laurocerasus officinalis Roem. (cherry laurel) by in vitro methods. Food Res Int. 2011;44:818-22.

[74] Ercetin T, Senol FS, Orhan IE, Toker G. Comparative assessment of antioxidant and cholinesterase inhibitory properties of the marigold extracts from Calendula arvensis L. and Calendula officinalis L. Ind Crop Prod. 2012;36: 203-8.

[75] Orhan IE, Senol FS, Gulpinar AR, Sekeroglu N, Kartal M, Sener B. Neuroprotective potential of some terebinth coffee brands and the unprocessed fruits of Pistacia terebinthus L. and their fatty and essential oil analyses. Food Chem. 2012;130:882-8.

[76] Sekeroglu N, Senol FS, Orhan IE, Gulpinar AR, Kartal M, Sener B. In vitro prospective effects of various traditional herbal coffees consumed in Anatolia linked to neurodegeneration. Food Res Int. 2012;45:197-203.

[77] Papandreou MA, Dimakopoulou A, Linardaki ZI, Cordopatis P, Klimis-Zacas D, Margarity M, Lamari FN. Effect of a polyphenol-rich wild blueberry extract on cognitive performance of mice, brain antioxidant markers and acetylcholinesterase activity. Behav Brain Res. 2009;198:352-8.

[78] Pereira DM, Ferreres F, Oliveira J, Valentão P, Andrade PB, Sottomayor M. Targeted metabolite analysis of Catharanthus roseus and its biological potential. Food ChemToxicol. 2009;47:1349-54.

[79] Pereira DM, Faria J, Gaspar L, Valentão P, Andrade PB. Boerhaavia diffusa: Metabolite profiling of a medicinal plant from Nyctaginaceae. Food Chem Toxicol. 2009; 47:2142-9.

[80] Mata AT, Proenc̃a C, Ferreira AR, Serralheiro MLM, Nogueira JMF, Araújo MEM. Antioxidant and acetylcholinesterase activities of five plants used as Portuguese food spices. Food Chem. 2007;103:778-86.

[81] Khadri A, Neffati M, Smiti S, Falé P, Lino ARL, Serralheiro MLM, Araújo MEM. Antioxidant, antiacetylcholinesterase and antimicrobial activities of Cymbopogon schoenanthus L. Spreng (lemon grass) from Tunisia. LWT - Food Science and Technology. 2010;43:331-6.

[82] Okello EJ, Savelev SU, Perry EK. In vitro anti- $\beta$-secretase and dual anti-cholinesterase activities of Camellia sinensis L. (tea) relevant to treatment of dementia. Phytother Res. 2004;18:624-7.

[83] Chung JH, Kim M, Kim HK. Green tea polyphenols suppress nitric oxide-induced apoptosis and acetylcholinesterase activity in human neuroblastoma cells. Nutr Res. 2005;25:477-83.

[84] Oboh G, Ademiluyi AO, Akinyemi AJ. Inhibition of acetylcholinesterase activities and some pro-oxidant induced lipid peroxidation in rat brain by two varieties of ginger (Zingiber officinale). Exp Toxicol Pathol. 2010; in Press.

[85] Hernandez MF, Falé PLV, Araújo MEM, Serralheiro MLM. Acetylcholinesterase inhibition and antioxidant activity of the water extracts of several Hypericum species. Food Chem. 2010;120:1076-82.

[86] Chen J, Long Y, Han M, Wang T, Chen Q, Wang R. Watersoluble derivative of propolis mitigates scopolamine-induced 
learning and memory impairment in mice. Pharmacol Biochem Behav. 2008;90:441-6.

[87] Buncharoen W, Saenphet S, Saenphet K. Acetylcholinesterase inhibitory effect of Pseuderanthemum palatiferum in Albino rats. Trends Res Sc Tech. 2010;2:13-8.

[88] Kaur T, Pathak CM, Pandhi P, Khanduja KL. Effects of green tea extract on learning, memory, behaviour and acetylcholinesterase activity in young and old male rats. Brain Cognit. 2008;67:25-30.

[89] Kim HK, Kim M, Kim S, Kim M, Chung JO. Effects of green tea polyphenol and cognitive and acetylcholinesterase activities. Biosci Biotechnol Biochem. 2004;68:1977-9.

[90] Willis LM, Shukitt-Hale B, Joseph JA. Recent advances in berry supplementation and age-related cognitive decline. Curr Opin Clin Nutr Metab Care. 2009;12:91.

[91] Francis ST, Head K, Morris PG, Macdonald IA. The effect of flavanol rich cocoa on the fMRI response to a cognitive task in healthy young people. J Cardiovasc Pharmacol. 2006;47:21520.

[92] Scholey A, French S, Morris P, Kennedy D, Milne A, Ha skell C. Consumption of cocoa flavanols results in acute improvements in mood and cognitive performance during sustained mental effort. J Psychopharmacol. 2010;10:1505-14.

[93] Spencer JPE. The impact of fruit flavonoids on memory and cognition. Br J Nutr. 2010;104:40-7.

[94] Pithayanukul P, Ruenraroengsak P, Bavovada R, Pakmanee N, Rutt Suttisri R, Saen-oon S. Inhibition of Naja kaouthia venom activities by plant polyphenols. J Ethnopharmacol. 2005;97:527-33.

[95] Singh IP, Bharate SB. Phloroglucinol compounds of natural origin. Nat Prod Rep. 2006;23:558-91.

[96] Yoon NY, Lee SH, Li Y, Kim SK. Phlorotannins from Ishige okamurae and their acetyl- and butyrylcholinesterases inhibitory effects. J Functional Foods. 2009;1:331-5.
[97] Stevanovic T, Diouf PN, Garcia-Perez ME. Bioactive Polyphenols from healthy diets and forest biomass. Curr Nutr Food Sci. 2009;5:264-95.

[98] Fan P, Terrier L, Hay A-E, Marston A, Hostettmann K. Antioxidant and enzyme inhibition activities and chemical profiles of Polygonum sachalinensis F.Schmidt ex Maxim (Polygonaceae). Fitoterapia. 2010;81:124-31.

[99] Spencer JPE, El Mohsen MMA, Rice-Evans C. Cellular uptake and metabolism of flavonoids and their metabolites: implications for their bioactivity. Arch Biochem and Biophys. 2004;423:148-61.

[100] Porfírio S, Falé PLV, Madeira PJA, Florêncio ME, Ascensão L, Serralheiro MLM. Antiacetylcholinesterase and antioxidant activities of Plectranthus barbatus tea, after in vitro gastrointestinal metabolism. Food Chem. 2010;122: 179-87.

[101] Pietta PG, Simonetti P, Gardana C, Brusamolino A, Morazzoni P, Bombardelli E. Catechin metabolites after intake of green tea infusions. BioFactors. 1998;8:111-8.

[102] Falé PLV, Madeira PJA, Florêncio ME, Ascensão L, Serralheiro MLM. Function of Plectranthus barbatus herbal tea as neuronal acetylcholinesterase inhibitor. Food \& Function. 2011;2:130-6

[103] Singh M, Arseneault M, Sanderson T, Murthy V, Ramassamy C. Challenges for research on polyphenols from foods in Alzheimer's disease: bioavailability, metabolism, and cellular and molecular mechanisms. J Agric Food Tech. 2008;56:4855-73.

[104] Nurk E, Refsum H, Drevon, CA, Tell GS, Nygaard HA, Engedal K, Smith AD. Cognitive performance among the elderly in relation to the intake of plant foods. The Hordaland Health Study. Br J Nutr. 2010;104:1190-201. 